University of Nebraska - Lincoln

DigitalCommons@University of Nebraska - Lincoln

\title{
Fluid Mechanics Education Using Japanese Anime: Examples from "Castle in the Sky" by Hayao Miyazaki
}

\author{
Sangjin Ryu \\ University of Nebraska-Lincoln, sangjin.ryu@unl.edu \\ Haipeng Zhang \\ University of Nebraska-Lincoln, haipeng.zhang@huskers.unl.edu \\ Markeya S. Peteranetz \\ University of Nebraska-Lincoln, peteranetz@unl.edu \\ Tareq Daher \\ University of Nebraska - Lincoln, tdaher2@unl.edu
}

Follow this and additional works at: https://digitalcommons.unl.edu/mechengfacpub

Part of the Mechanics of Materials Commons, Nanoscience and Nanotechnology Commons, Other Engineering Science and Materials Commons, and the Other Mechanical Engineering Commons

Ryu, Sangjin; Zhang, Haipeng; Peteranetz, Markeya S.; and Daher, Tareq, "Fluid Mechanics Education Using Japanese Anime: Examples from "Castle in the Sky" by Hayao Miyazaki" (2020). Mechanical \& Materials Engineering Faculty Publications. 505.

https://digitalcommons.unl.edu/mechengfacpub/505

This Article is brought to you for free and open access by the Mechanical \& Materials Engineering, Department of at DigitalCommons@University of Nebraska - Lincoln. It has been accepted for inclusion in Mechanical \& Materials Engineering Faculty Publications by an authorized administrator of DigitalCommons@University of Nebraska Lincoln. 


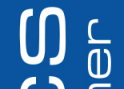 Anime: Examples from "Castle in the Sky" by Hayao Miyazaki}

Fluid Mechanics Education Using Japanese

Cite as: Phys. Teach. 58, 230 (2020); https://doi.org/10.1119/1.5145464

Published Online: 19 March 2020

Sangjin Ryu, Haipeng Zhang, Markeya Peteranetz, and Tareq Daher

\section{ARTICLES YOU MAY BE INTERESTED IN}

\section{BUOYANCIES}

The Physics Teacher 58, 228 (2020); https://doi.org/10.1119/1.5145463

Is Modern Cosmology in Crisis?

The Physics Teacher 58, 234 (2020); https://doi.org/10.1119/1.5145465

Collision of a Ball with a Stationary Oscillator

The Physics Teacher 58, 241 (2020); https://doi.org/10.1119/1.5145467

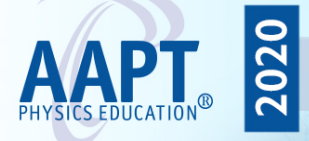




\section{Fluid Mechanics Education Using Japanese Anime: Examples from "Castle in the Sky" by Hayao Miyazaki}

Sangjin Ryu, Haipeng Zhang, Markeya Peteranetz, and Tareq Daher, University of Nebraska-Lincoln, Lincoln, NE

$\mathrm{C}$ urrent K-12 and undergraduate students have grown up with constant exposure to visual popular culture (e.g., movies, TV programs, graphic novels, etc.). Because youth find pop culture references in the classroom to be engaging, many science and engineering instructors have shown that examples found in visual pop culture can be used to teach science and engineering concepts. ${ }^{1,2}$ One recent study on the efficacy of using pop culture for instruction found that high school students learning from graphic-novel style comics acquired deeper understanding of complex subject matter and reported higher engagement with the instructional materials as compared to students learning from traditional text materials. ${ }^{3}$ Furthermore, the increased engagement with the instructional comics was even greater for students who were less likely to self-identify as a "science person."

Japanese animation, or anime, is one genre of visual pop culture that has steadily gained popularity in the United States, ${ }^{4,5}$ and many traditionally aged college students were exposed to anime as children through popular franchises (e.g., Pokémon, Yu-Gi-Oh!, Dragon Ball, and Naruto) and anime conventions held in many cities. However, compared to other types of visual pop culture, there is far less literature describing how anime can be used to curate instructional examples. In this paper, we suggest using examples found in anime for teaching fluid mechanics, a branch of physics dealing with fluids, to college students.

Anime has been incorporated into foreign-language instruction, for learning both English ${ }^{5}$ and Japanese. ${ }^{6}$ Other types of visual pop culture have been used across a range of subjects (e.g., chemistry, ${ }^{7}$ biology, ${ }^{8}$ physics, ${ }^{9}$ and business eth$\left.\mathrm{ics}^{10}\right)$. Bringing visual pop culture into the classroom can help to create a common experience among students that can then be used as an anchor for learning key concepts while connecting with students' interests and increasing engagement. ${ }^{2} \mathrm{An}-$ imation can be useful for teaching physics, because although animation generally reflects reality, it is less constrained by reality than is live-action media, and this potential for separation from reality provides opportunities to test the extent to which principles of physics are bent in the "world" of the animated characters. ${ }^{9}$ Anime is one class of animation that has been underexplored as a source of novel, engaging examples for teaching physics. Next, we present three specific examples of how concepts in fluid mechanics can be presented and taught through scenes in one anime movie.

The most well-known Japanese animator is Hayao Miyazaki. ${ }^{11}$ Through his anime movies, Miyazaki has consistently
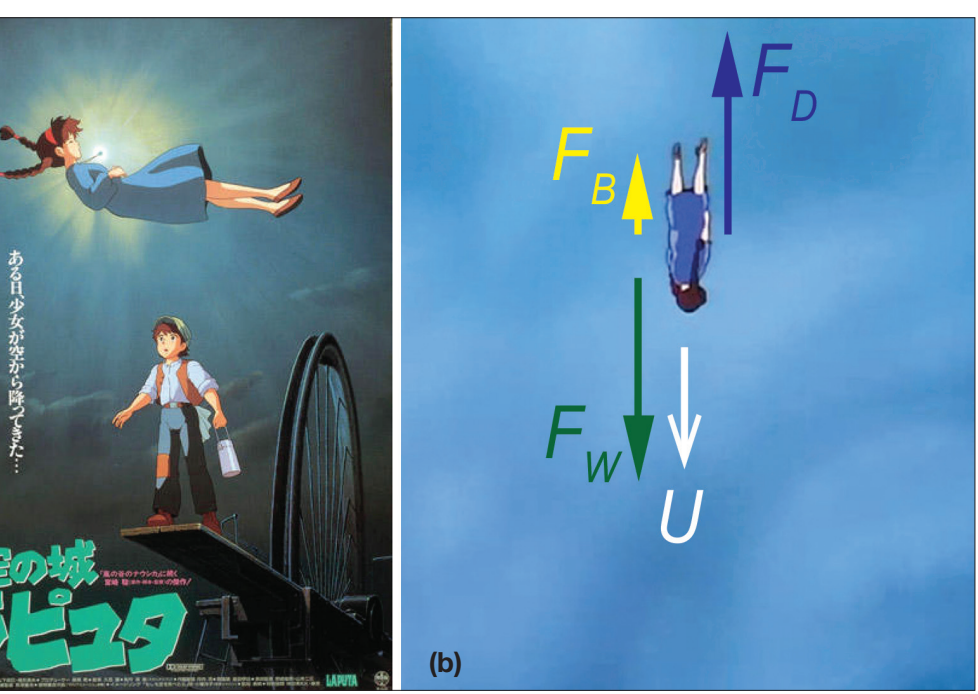

Fig. 1. (a) Poster of "Castle in the Sky" directed by Hayao Miyazaki (๑ 1986 Studio Ghibli) shows that Sheeta falls with her magic crystal amulet (supine position) as watches. (b) Fluid mechanics forces on falling Sheeta (vertical position). As the force arrows (not to scale) indicate, $F_{B}$ is very small compared to $F_{W}$ as expressed his love for aircraft and things that fly. Therefore, his movies can easily be incorporated in lectures about fluid mechanics. In this paper, we introduce examples of fluid mechanics in Miyazaki's "Castle in the Sky" [Fig. 1(a)], which is enjoyable to various age groups and contains many fluid mechanics-related scenes. In this anime movie, a young girl named Sheeta has a magic crystal amulet race with a brave boy named Pazu against air pirates and secret agents in their search for a legendary floating castle, Laputa.

\section{Buoyancy, drag force, and terminal speed of falling Sheeta}

The first example is the free fall of Sheeta. She falls from the airplane after she was kidnapped by the agents. During the free fall, she experiences three force components [Fig. 1(b)]. First, body weight $\left(F_{\mathrm{W}}\right)$ from gravity drives the free fall, which depends on the body volume: $F_{\mathrm{W}}=\rho_{\text {body }} g V=m g$, where $\rho_{\text {body }}$ is the density of her body, $g$ the acceleration of gravity, $V$ the body volume, and $m$ the body mass. Second, the buoyant force $\left(F_{\mathrm{B}}\right)$ is the upward force of air displaced by the body, in which $F_{\mathrm{B}}$ also depends on $V$ because it is equal to the weight of air displaced by the body: $F_{\mathrm{B}}=\rho_{\text {air }} g V$, where $\rho_{\text {air }}$ is the density of $\operatorname{air}\left(=1.2 \mathrm{~kg} / \mathrm{m}^{3}\right)$. Last, the drag force $\left(F_{\mathrm{D}}\right)$ is the aerodynamic resistance from the surrounding air. $F_{\mathrm{D}}$ is estimated via the drag coefficient, $C_{D}$ :

$$
F_{\mathrm{D}}=C_{\mathrm{D}} \cdot \frac{1}{2} \rho_{\text {air }} U^{2} \cdot A,
$$


where $A$ is the reference area of the body in the direction of the motion. $U$ is the terminal speed (i.e., zero acceleration) of the unconscious girl, which is determined by the force balance among the three forces $\left(F_{\mathrm{W}}=F_{\mathrm{B}}+F_{\mathrm{D}}\right)$.

Then, $U$ is determined to be

$$
U=\sqrt{2\left(\frac{\rho_{\text {body }}-\rho_{\text {air }}}{\rho_{\text {air }}}\right) \frac{V g}{C_{\mathrm{D}} A}} \stackrel{\rho_{\text {body }}>>\rho_{\text {air }}}{\longrightarrow} U=\sqrt{\frac{2 m g}{\rho_{\text {air }} C_{\mathrm{D}} A}} .
$$

Since $\rho_{\text {air }} m$, and $g$ are constant, $U$ depends on the product of $C_{\mathrm{D}}$ and $A$ only: as $C_{\mathrm{D}} A$ increases, which means larger drag on the body, $U$ decreases. It needs to be noted that $C_{\mathrm{D}} A$ changes as the falling posture of Sheeta changes. For the vertical orientation (head-down position) shown in Fig. 1(b), $C_{\mathrm{D}} A$ is $0.11 \mathrm{~m}^{2}$ for an average adult. ${ }^{13}$ We converted this $C_{\mathrm{D}} A$ value for Sheeta because Sheeta has a smaller $A$ value than adults. Here, it needs to be noted $C_{\mathrm{D}}$ does not depend on the body size because it is dimensionless. Assuming an average height of $1.75 \mathrm{~m}$ and $1.55 \mathrm{~m}$ for adults and 13.5-year-old girls, respectively, ${ }^{14}$ we evaluated the area ratio between Sheeta and an average adult to be $A_{\text {Sheeta }} / A_{\text {adult }}=(1.55 \mathrm{~m} / 1.75 \mathrm{~m})^{2}=$ 0.784 . Then, the $C_{\mathrm{D}} A$ value of Sheeta is found as follows: $C_{\mathrm{D}} A-$ Sheeta $=C_{\mathrm{D}} A_{\text {adult }}\left(A_{\text {Sheeta }} / A_{\text {adult }}\right)=0.086 \mathrm{~m}^{2}$. Then, the terminal speed is estimated to be $95.4 \mathrm{~m} / \mathrm{s}$ with the average $m$ of 48 $\mathrm{kg}$ for the girl, which is worrisome for viewers.

Fortunately, Sheeta's crystal amulet is activated and changes her posture (belly-to-sky or supine position) as shown in Fig. 1(a). For this posture, the $C_{\mathrm{D}} A$ of an average adult is 0.84 $\mathrm{m}^{2}$, and thus the $C_{\mathrm{D}} A$ of Sheeta is estimated to be $0.659 \mathrm{~m}^{2} .{ }^{13}$ As a result, the terminal speed has decreased to $34.5 \mathrm{~m} / \mathrm{s} \mathrm{ac}-$ cording to Eq. (2). This is exactly what skydivers do to slow down their free fall. Here, it needs to be mentioned that the crystal amulet also appears to reduce the $g$ value in Eq. (2) or to generate anti-gravity field since the material is used to keep the castle Laputa and the other flying cities aloft.

It should also be pointed out that $C_{\mathrm{D}}$ depends on the Reynolds number $\left(R e=\rho_{\text {air }} U L / \mu_{\text {air }}\right)$ and Mach number $(M a=U / a)$ of Sheeta falling in the air. Here, $\mu_{\text {air }}$ is the dynamic viscosity of air $\left(=1.8 \times 10^{-5} \mathrm{~Pa} \cdot \mathrm{s}\right), L$ the characteristic length scale of Sheeta, and $a$ the speed of sound in air $(=340 \mathrm{~m} / \mathrm{s})$. For the head-down posture, we can assume Sheeta's shoulder width for $L(=0.4 \mathrm{~m})$, and the $R e$ and $M a$ of falling Sheeta are calcu-
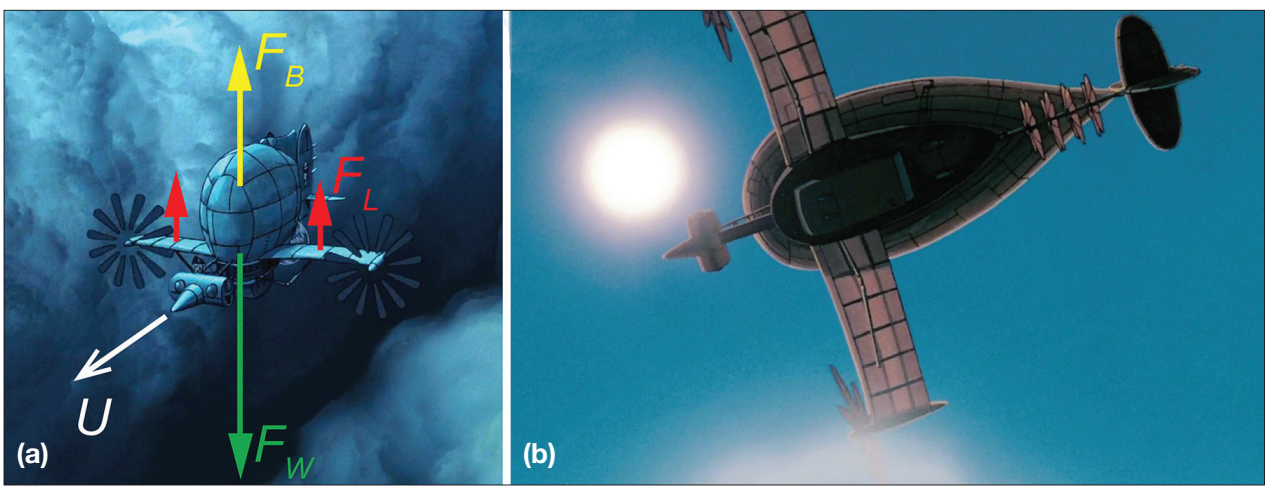

Fig. 2. (a) Forces on the Tiger Moth. $F_{\mathrm{B}}=$ buoyant force, $F_{\mathrm{L}}=$ lift force, $F_{\mathrm{W}}=$ weight, and $U=$ flight speed. The force arrows are not to scale. (b) Streamlined profile of the Tiger Moth. Reproduced from "Castle in the Sky" (@ 1986 Studio Ghibli). ${ }^{12}$ lated to be $2.5 \times 10^{6}$ and 0.28 , respectively. These $R e$ and $M a$ values show that the airflow around falling Sheeta is subsonic turbulent flow. ${ }^{13}$ Since the used $C_{\mathrm{D}}$ values are valid for incompressible flow of $R e>10^{4}$, our calculation of $U$ is justified.

\section{Lift force on the Tiger Moth}

The main ship of the air pirate is the Tiger Moth, shown in Fig. 2(a). This aircraft can fly based on two fluid mechanics forces. First, the main body has balloons filled with helium, which is lighter than air, so the Tiger Moth is similar to hot air balloons and a blimp in the sense that its flight relies on the buoyant force $\left(F_{\mathrm{B}}\right)$ generated by the lighter gas and the larger volume of the main body. However, having the balloons is not enough for the aircraft to "fly" because the buoyant force does not generate propulsion. So, the Tiger Moth has two wings with rotors to produce propulsion and lift force $\left(F_{\mathrm{L}}\right)$. Then, it can be questioned which force is larger between the two and whether these forces are enough to fly the air pirate ship in the air.

The Tiger Moth is $42 \mathrm{~m}$ long, $20 \mathrm{~m}$ high, and $54 \mathrm{~m}_{\text {wide. }}{ }^{15}$ Based on these dimensions and available images, we estimate that the volume of the balloon is about $1810 \mathrm{~m}^{3}$ as an ellipsoid of the diameter and length of $12 \mathrm{~m}$ and $24 \mathrm{~m}$, respectively [i.e., $\left.V=(4 \pi / 3) \times(24 \mathrm{~m} / 2) \times(12 \mathrm{~m} / 2)^{2}\right]$. In this case, $F_{B}$ is found to be about $2.13 \times 10^{4} \mathrm{~N}$. The lift force generated by an airfoil is given as

$$
F_{\mathrm{L}}=C_{\mathrm{L}} \cdot \frac{1}{2} \rho_{\text {air }} U^{2} \cdot A,
$$

where $C_{\mathrm{L}}$ is the lift coefficient, $U$ the flight speed, and $A$ the area of the airfoil. Again, based on the available dimensions and images of the Tiger Moth, we estimate that the chord and span of one wing are $6.2 \mathrm{~m}$ and $15.4 \mathrm{~m}$, respectively (i.e., $A=95.5 \mathrm{~m}^{2}$ ). The average speed of the aircraft is $65 \mathrm{~km} / \mathrm{h}$ $(=18.1 \mathrm{~m} / \mathrm{s})$, and the typical maximum $C_{\mathrm{L}}$ value of cambered membrane wings is about $1^{16}$. As such, we estimate that the two wings can generate $F_{\mathrm{L}}$ of $3.75 \times 10^{4} \mathrm{~N}$ in total, which is higher than the $F_{\mathrm{B}}$ of the balloon.

These calculations indicate that both forces are important for the flight of the air pirates, and that the force can lift a total mass of about $6000 \mathrm{~kg}$ into the air. Here, it needs to be noted that $F_{\mathrm{L}}$ is proportional to $U^{2}$, whereas $F_{\mathrm{B}}$ does not depend on $U$, which means that if the Tiger Moth flies slowly, the aircraft relies more on $F_{\mathrm{B}}$. Although the helium-filled body is crucial for the flight of the Tiger Moth, its size can cause significant drag on the aircraft. Seen from the front [Fig. 2(a)], the balloon looks quite massive, which implies a high $C_{\mathrm{D}} A$ value. However, when seen from the bottom [Fig. 2(b)], the body is actually streamlined to reduce $C_{\mathrm{D}}$.

\section{Flowlines on Pazu}

When Pazu and Sheeta escape 


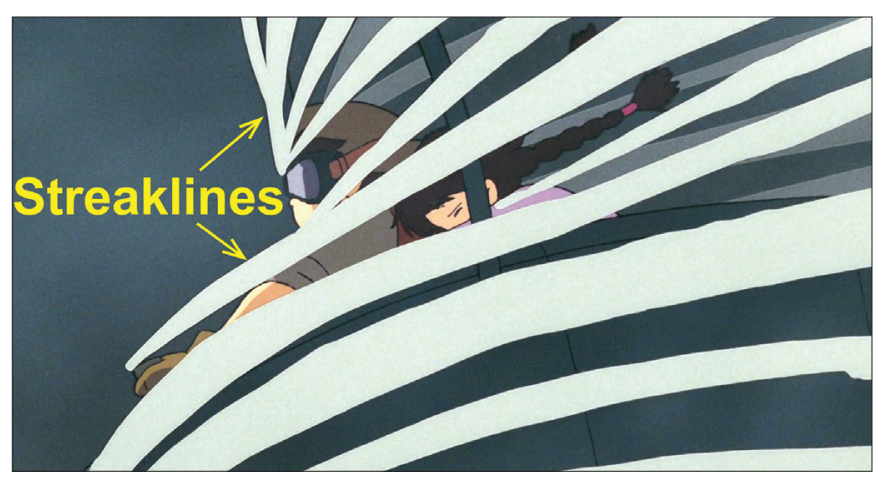

Fig. 3. Streaklines formed around Pazu by cloudlets. Reproduced from "Castle in the Sky" (C) 1986 Studio Ghibli). ${ }^{12}$

the thick cloud surrounding the floating castle of Laputa, we can see airflow visualized by the cloudlets around Pazu's face (Fig. 3). Since clouds are composed of water droplets, the motion of condensed droplets can visualize the airflow around the face. Flow visualization is a critical technique for fluid mechanics since most fluids are transparent and thus their motion is invisible. One easy way to visualize invisible flow is to introduce a dye in the flow. In this example, the cloud plays this role.

There are four flowlines for fluid mechanics: streamline, streakline, pathline, and timeline. A streamline is a line tangential to velocity vectors in a flow velocity field at a given instant. A streakline is a line formed by particles released from a certain point in the flow field. A pathline is the actual path drawn by one single particle moving in the flow field. A timeline is a line connecting a set of particles that are released simultaneously and move together in the flow field at a certain instant. Based on these definitions, the flowline in Fig. 3 seems to be streaklines since the figure shows a snapshot of cloud streak originating from specific locations.

\section{Students' responses to anime examples}

We used the suggested examples along with other anime-based examples in an undergraduate-level fluid mechanics class, and at the end of the semester we asked students how they thought about the examples and the approach. Students' feedback was valuable because we did not initially know how the use of these examples would be seen by students. Here are some comments from students:

- "It was enjoyable and gave a good example to practice making 'reasonable assumptions' around a 'real world' application."

- "They're cool, just like any real-world or fictional relations they make you ask questions about realistic events of fluid mechanics."

- "Very interesting and engaging! Helped me maintain attention and showed practical application of theory."

- "They were great ways to easily visualize our theoretical knowledge in a somewhat practical way."

- "I think they help me understand the concepts better because it is more intriguing than just equations. I seem to pay attention better."
- "They were interesting and gave further insight on how to apply fluid mechanics to real life examples."

- "I thought that the anime examples were very intriguing. It made learning fun and interesting which does not happen a lot in engineering."

As shown by these responses, the larger number of students were for using anime for teaching fluid mechanics because the examples made them more engaged with the content that they learned and provided a break from the normal methods of teaching. Also, many students thought that they could transfer knowledge to real-world applications. This response is very encouraging because we were aware of the risk of students not being able to transfer knowledge, yet we believed that their engagement with the examples allowed them to better grasp the concepts. Some students gave suggestions on how to improve using anime examples: balance between fictional examples and non-fictional examples, and diversifying anime examples.

\section{Summary}

Many physics teachers look for ways to include visual pop culture in their instruction because it is a source of countless novel examples that capture students' attention and connect with their personal interests. Japanese animation is a distinctive genre that is widely enjoyed by people around the world, but it is less commonly used to supplement instruction than other types of visual media. The three examples from Hayao Miyazaki's "Castle in the Sky" presented here show that examples of fluid mechanics can be extracted from anime and analyzed for instructional purposes with key assumptions summarized in Table I. The concepts in these examples include

Table I. Key assumptions made for the shown calculations.

\begin{tabular}{|c|c|}
\hline $\begin{array}{l}\text { Buoyancy, drag } \\
\text { force, and } \\
\text { terminal speed } \\
\text { of falling } \\
\text { Sheeta }\end{array}$ & $\begin{array}{l}\text { 1. } C_{\mathrm{D}} \text { is assumed to be equivalent between } \\
\text { young girls and adult males, and not affected } \\
\text { by outfits. } \\
\text { 2. Sheeta is assumed to have average height and } \\
\text { weight of } 13 \text { - to } 14 \text {-year-old Japanese girls. } \\
\text { 3. The average height of adults is assumed to be } \\
1.75 \mathrm{~m} \text {. } \\
\text { 4. Scaling proportionality is assumed between } \\
\text { Sheeta and average adult in terms of dimen- } \\
\text { sion. }\end{array}$ \\
\hline $\begin{array}{l}\text { Lift force on } \\
\text { the Tiger Moth }\end{array}$ & $\begin{array}{l}\text { 1. The helium balloon is mainly responsible } \\
\text { for the buoyance force, so the buoyancy of } \\
\text { other parts of the aircraft is assumed to be } \\
\text { negligible. } \\
\text { 2. Although the helium balloon section consists } \\
\text { of three balloon compartments, it is assumed } \\
\text { as an ellipsoid for easier calculation of vol- } \\
\text { ume. } \\
\text { 3. The maximum } C_{\mathrm{L}} \text { of the wings of the Tiger } \\
\text { Moth is assumed to be } 1 \text {. }\end{array}$ \\
\hline $\begin{array}{l}\text { Common } \\
\text { assumption }\end{array}$ & $\begin{array}{l}\text { 1. The properties of air }\left(\rho_{\text {air }} \mu_{\text {air }} \text { and } a \text { ) are as- }\right. \\
\text { sumed to be constant regardless of altitude. }\end{array}$ \\
\hline
\end{tabular}


buoyant force, drag and lift, key dimensionless numbers such as Reynolds number and Mach number, streamlined shape for drag reduction, and flow visualization and streakline. Though anime has been used less frequently than other types of visual pop culture, it has rich potential as a source of instructional examples that illustrate concepts from fluid dynamics and other areas of physics. Examples drawn from anime are likely to be novel to many students as it is more common for pop culture-based examples to be drawn from more mainstream sources.

\section{Acknowledgment}

SR and HZ appreciate Mark Griep and Rachel Pepper for their reading of and suggestion for the manuscript, and Kawasaki Reading Room of the University of Nebraska-Lincoln and Madoka Wayoro for their support.

\section{References}

1. L. W. Dubeck, M. H. Bruce, J. S. Schmuckler, S. E. Moshier, and J. E. Boss, "Science fiction aids science teaching," Phys. Teach. 28, 316-318 (May 1990); A. E. Segall, "Science fiction in the engineering classroom to help teach basic concepts and promote the profession," J. Eng. Educ. 91, 419-423 (2002); M. L. Dark, "Using science fiction movies in introductory physics," Phys. Teach. 43, 463-465 (Oct. 2005); C. Efthimiou and R. A. Llewellyn, "Avatars of Hollywood in physical science," Phys. Teach. 44, 28-33 (Jan. 2006); S. Laprise and C. Winrich, "The impact of science fiction films on student interest in science," J. Coll. Sci. Teach. 40, 45-49 (2010).

2. C. A. Frey, M. L. Mikasen, and M. A. Griep, "Put some movie wow! in your chemistry teaching," J. Chem. Educ. 89, 11381143 (2012).

3. A. N. Spiegel, J. McQuillan, P. Halpin, C. Matuk, and J. Diamond, "Engaging teenagers with science through comics," Res. Sci. Educ. 43, 2309-2326 (2013).

4. H. Furo, "Using anime as a teaching tool in U.S. undergraduate course," in 3rd International Conference of WorldCALL (The Japan Association for Language Education and Technology, Fukuoka, Japan, 2008); D. R. Rich, "Global fandom: The circulation of Japanese popular culture in the U.S.," The University of Iowa, 2011.

5. J. Ruble and K. Lysne, "The animated classroom: Using Japanese Anime to engage and motivate students," English J. 100, 37-46 (2010).

6. N. Fukunaga, “'Those anime students': Foreign language literacy development through Japanese popular culture," J. Adolesc. Adult Lit. 50, 206-222 (2006); Y.-H. Chan, N.-L. Wong, and L.-L. Ng, "Japanese language students' perception of using anime as a teaching tool," Indones. J. Appl. Linguist. 7, 93-104 (2017).

7. M. A. Griep and M. L. Mikasen, "Using movie clips to teach chemistry formally and informally," in Hollywood Chemistry: When Science Met Entertainment, edited by D. J. Nelson, K. R. Grazier, J. Paglia, and S. Perkowitz (American Chemical Society, 2013).

8. J. Hosler and K. B. Boomer, "Are comic books an effective way to engage nonmajors in learning and appreciating science?" CBE-Life Sci. Educ. 10, 309-317 (2011).

9. M. Rogers, "An inquiry-based course using 'Physics?' in cartoons and movies," Phys. Teach. 45, 38-41 (Jan. 2007).
10. V. W. Gerde and R. S. Foster, "X-Men ethics: Using comic books to teach business ethics," J. Bus. Ethics 77, 245-258 (2008).

11. H. McCarthy, Hayao Miyazaki: Master of Japanese Animation (Stone Bridge Press, Berkeley, CA, 1999).

12. “Castle in the Sky”, (天空の城ラピュタ), directed by H. Miyazaki (宮崎 駿), Studio Ghibli (スタジオジブリ), (1986), http://www.ghibli.jp/.

13. R. D. Blevins, Applied Fluid Dynamics Handbook (Van Nostrand Reinhold Co., New York, 1984).

14. スクスクのっぽくん (June 29, 2018), https://www. suku-noppo.jp/data/.

15. Laputa Roman Album Extra (Tokuma Shoten, Japan, 2002).

16. A. H. Wrist and J. P. Hubner, "Aerodynamic comparisons of flexible membrane micro air vehicle wings with cambered and flat frames," Int. J. Micro Air Veh. 10, 12-30 (2018).

Sangjin Ryu is an associate professor with the Department of Mechanical and Materials Engineering, the University of Nebraska-Lincoln (UNL). He received $B S$ and $M S$ degrees in mechanical engineering from Seoul National University, Seoul, South Korea, respectively, and the PhD in mechanical engineering from MIT, Cambridge, ME. Before joining UNL, he worked as a postdoctoral researcher at Brown University, Providence, RI. At UNL, Dr. Ryu teaches fluid mechanics courses both at the undergraduate and graduate levels. In 2019 he received UNL College Distinguished Teaching Award/Holling Family Master Teacher Award, and was chosen as the Outstanding Mechanical \& Materials Engineering Faculty by UNL Pi Tau Sigma. His research interests include microfluidics and interfacial fluid dynamics, and he also gives informal engineering lectures on Japanese animation under the title of "Professor Otaku." sangjin.ryu@unl.edu

Haipeng Zhang is currently a PhD student in the Department of Mechanical and Materials Engineering, University of Nebraska-Lincoln. He received the $B S$ degree in mechanical engineering from Kitami Institute of Technology, Kitami, Japan, in 2007, and the MS degree in mechanical engineering and applied mechanics from UNL in 2018. He also worked for Kubota Corporation (Japan) in Beijing, China, for 2009-2015. He was the recipient of a Graduate Student Scholarship Award from the ASME Fluids Engineering Division for ASME-JSEM-KSME Joint Fluids Engineering Conference (2019).

Markeya Peteranetz is the learning assessment coordinator for the College of Engineering. Markeya earned her bachelor's degree in psychology from the University of Nebraska at Kearney. She earned her master's degree and PhD in the Department of Educational Psychology at the University of Nebraska-Lincoln. As the learning assessment coordinator, she works to address engineering faculty's assessment needs, conducts engineering education research, and leads and supports various assessment and evaluation projects across the college.

Tareq Daher graduated from the University of Mutah-Jordan with a BS in computer science with a focus on creating educational tools. He pursued a master's degree in instructional technology at the University of Nebraska-Lincoln (UNL). While pursing his master's degree, he worked as the coordinator for the student technology program on the UNL campus, where he taught over 150 workshops on technology uses in the classroom to faculty, staff, and students. He completed his PhD in educational studies with a focus on instructional technology from UNL and is currently serving as the director of the Engineering and Computing Education Core, College of Engineering, UNL, helping to transform engineering education in the college through graduate courses, faculty professional development, and educational research. 